\title{
Preoperative Chemoradiotherapy for Esophageal or Junctional Cancer
}

\author{
P. van Hagen, M.C.C.M. Hulshof, J.J.B. van Lanschot, E.W. Steyerberg, \\ M.I. van Berge Henegouwen, B.P.L. Wijnhoven, D.J. Richel, \\ G.A.P. Nieuwenhuijzen, G.A.P. Hospers, J.J. Bonenkamp, M.A. Cuesta, \\ R.J.B. Blaisse, O.R.C. Busch, F.J.W. ten Kate, G.J. Creemers, C.J.A. Punt, \\ J.T.M. Plukker, H.M.W. Verheul, E.J. Spillenaar Bilgen, H. van Dekken, \\ M.J.C. van der Sangen, T. Rozema, K. Biermann, J.C. Beukema, \\ A.H.M. Piet, C.M. van Rij, J.G. Reinders, H.W. Tilanus, \\ and $A$. van der Gaast, for the CROSS Group*
}

The authors' full names, degrees, and affiliations are listed in the Appendix. Address reprint requests to $D r$. van der Gaast at the Department of Medical Oncology, Erasmus University Medical Center/Daniel den Hoed Cancer Center, P.O. Box 2040, 3000 CA Rotterdam, the Netherlands, or at a.vandergaast@erasmusmc.nl.

*The members of the Chemoradiotherapy for Oesophageal Cancer Followed by Surgery Study (CROSS) Group are listed in the Supplementary Appendix, available at NEJM.org.

N Engl J Med 2012;366:2074-84. Copyright (C) 2012 Massachusetts Medical Society.

\section{A BSTRACT}

\section{BACKGROUND}

The role of neoadjuvant chemoradiotherapy in the treatment of patients with esophageal or esophagogastric-junction cancer is not well established. We compared chemoradiotherapy followed by surgery with surgery alone in this patient population.

\section{METHODS}

We randomly assigned patients with resectable tumors to receive surgery alone or weekly administration of carboplatin (doses titrated to achieve an area under the curve of $2 \mathrm{mg}$ per milliliter per minute) and paclitaxel (50 mg per square meter of body-surface area) for 5 weeks and concurrent radiotherapy (41.4 Gy in 23 fractions, 5 days per week), followed by surgery.

RESULTS

From March 2004 through December 2008, we enrolled 368 patients, 366 of whom were included in the analysis: 275 (75\%) had adenocarcinoma, 84 (23\%) had squamous-cell carcinoma, and 7 ( $2 \%$ ) had large-cell undifferentiated carcinoma. Of the 366 patients, 178 were randomly assigned to chemoradiotherapy followed by surgery, and 188 to surgery alone. The most common major hematologic toxic effects in the chemoradiotherapy-surgery group were leukopenia (6\%) and neutropenia (2\%); the most common major nonhematologic toxic effects were anorexia (5\%) and fatigue (3\%). Complete resection with no tumor within $1 \mathrm{~mm}$ of the resection margins (R0) was achieved in $92 \%$ of patients in the chemoradiotherapy-surgery group versus $69 \%$ in the surgery group $(\mathrm{P}<0.001)$. A pathological complete response was achieved in 47 of 161 patients (29\%) who underwent resection after chemoradiotherapy. Postoperative complications were similar in the two treatment groups, and in-hospital mortality was $4 \%$ in both. Median overall survival was 49.4 months in the chemoradiotherapysurgery group versus 24.0 months in the surgery group. Overall survival was significantly better in the chemoradiotherapy-surgery group (hazard ratio, $0.657 ; 95 \%$ confidence interval, 0.495 to $0.871 ; \mathrm{P}=0.003$ ).

\section{CONCLUSIONS}

Preoperative chemoradiotherapy improved survival among patients with potentially curable esophageal or esophagogastric-junction cancer. The regimen was associated with acceptable adverse-event rates. (Funded by the Dutch Cancer Foundation [KWF Kankerbestrijding]; Netherlands Trial Register number, NTR487.) 
ITH NEW DIAGNOSES IN MORE THAN 480,000 patients annually, esophageal cancer is the eighth most common cancer worldwide. ${ }^{1}$ It is a highly lethal disease, causing more than 400,000 deaths per year. ${ }^{2}$ The incidence of esophageal adenocarcinoma is rapidly rising, whereas that of squamous-cell carcinoma remains unchanged. ${ }^{3}$ Despite adequate preoperative staging, $25 \%$ of patients treated with primary surgery have microscopically positive resection margins (R1), and the 5-year survival rate rarely exceeds $40 \% .^{4}$

The role of neoadjuvant chemoradiotherapy has been debated for several decades. In most randomized trials, no survival benefit could be shown, and the trials were criticized for inadequate trial design, samples that were too small, and poor outcomes in the surgery-alone group. Meta-analyses suggest a survival benefit from neoadjuvant chemoradiotherapy, albeit frequently at the cost of increased postoperative morbidity and mortality. ${ }^{5,6}$

We previously reported a phase 2 trial of neoadjuvant chemoradiotherapy consisting of weekly administration of carboplatin and paclitaxel with concurrent radiotherapy. ${ }^{7}$ This regimen was associated with a low rate of serious toxic effects, and a complete resection with no tumor within $1 \mathrm{~mm}$ of the resection margins (R0) was achieved in all patients who underwent resection. These results encouraged us to initiate a multicenter, randomized, controlled, phase 3 study comparing neoadjuvant chemoradiotherapy followed by surgery with surgery alone in patients with potentially curable esophageal or esophagogastricjunction carcinoma. ${ }^{8}$

\section{METHODS}

\section{ELIGIBILITY CRITERIA}

Patients with histologically confirmed, potentially curable squamous-cell carcinoma, adenocarcinoma, or large-cell undifferentiated carcinoma of the esophagus or esophagogastric junction (i.e., tumors involving both the cardia and the esophagus on endoscopy) were eligible for inclusion in the study. The upper border of the tumor had to be at least $3 \mathrm{~cm}$ below the upper esophageal sphincter. Patients who had proximal gastric tumors with minimal invasion of the esophagus were excluded. The length and width of the tumor could not exceed $8 \mathrm{~cm}$ and $5 \mathrm{~cm}$, respectively. Only patients with tumors of clinical stage $\mathrm{T} 1 \mathrm{~N} 1$ or $\mathrm{T} 2-3 \mathrm{~N} 0-1$ and no clinical evidence of metastatic spread (M0), according to the International Union against Cancer (UICC) tumor-node-metastasis (TNM) classification, ${ }^{9}$ were enrolled. Eligible patients were 18 to 75 years of age, had a World Health Organization (WHO) performance status score of 2 or lower (on a scale of 0 to 5 , with 0 indicating fully active, 1 unable to carry out heavy physical work, and 2 up and about more than half the day but unable to work), and had lost $10 \%$ or less of body weight. Patients also had to have adequate hematologic, renal, hepatic, and pulmonary function, as well as no history of other cancer or previous radiotherapy or chemotherapy.

All patients provided written informed consent. The institutional review board at each participating center approved the study protocol. ${ }^{8}$ The protocol, including the statistical analysis plan, is available with the full text of this article at NEJM.org. No commercial support was involved in the study; the drugs were purchased. No one who is not an author contributed to the manuscript. The first, fourth, and last authors vouch for the accuracy and completeness of the reported data and the fidelity of the study to the protocol.

\section{STAGING}

All patients underwent pretreatment staging. This included a history taking; physical examination; pulmonary-function tests, routine hematologic and biochemical tests; upper gastrointestinal endoscopy with histologic biopsy and endoscopic ultrasonography; computed tomography of the neck, chest, and upper abdomen; and external ultrasonography of the neck, with fine-needle aspiration of lymph nodes when cancer was suspected. For the final analysis, the available endoscopic reports were centrally reviewed.

\section{TREATMENT}

\section{Chemotherapy}

On days 1, 8, 15, 22, and 29, carboplatin targeted at an area under the curve of $2 \mathrm{mg}$ per milliliter per minute and paclitaxel at a dose of $50 \mathrm{mg}$ per square meter of body-surface area were administered intravenously. All patients were intravenously premedicated with dexamethasone, clemastine, and ranitidine as well as standard antiemetic agents. The patients were closely monitored for toxic effects of chemotherapy with the use of the National Cancer Institute's Common Terminology Criteria for Adverse Events, version 3.0. ${ }^{10}$ 


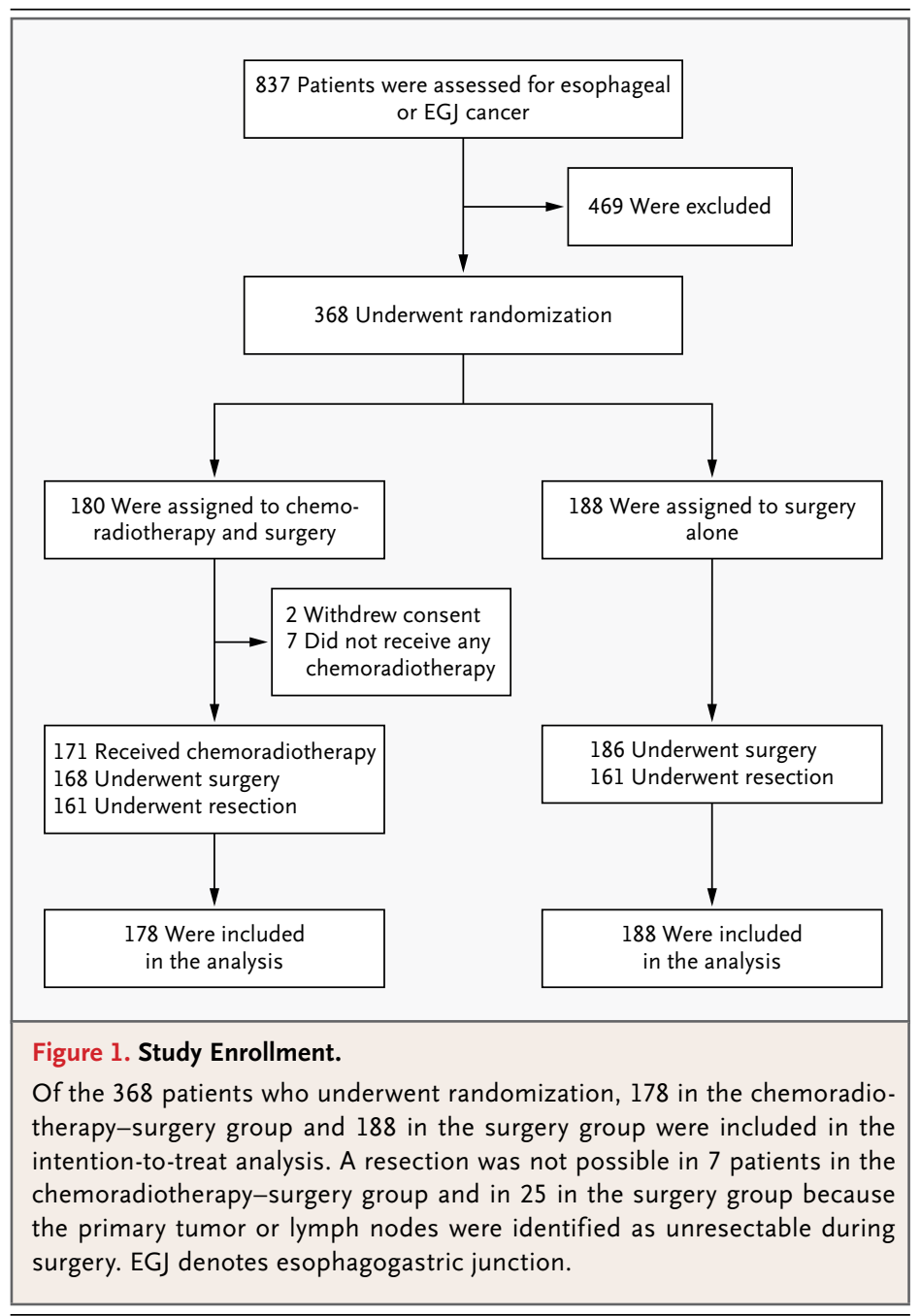

\section{Radiotherapy}

A total radiation dose of 41.4 Gy was given in 23 fractions of 1.8 Gy each, with 5 fractions administered per week, starting on the first day of the first chemotherapy cycle. All patients were treated by means of external-beam radiation. A detailed description of the methods of administration of chemotherapy and radiotherapy can be found in Appendix 1 in the Supplementary Appendix, available at NEJM.org.

\section{Surgery}

Patients in the chemoradiotherapy-surgery group underwent surgery as soon as possible after completion of chemoradiotherapy (preferably, within 4 to 6 weeks), and patients in the surgery group were treated as soon as possible after randomization. A transthoracic approach with two-field lymph-node dissection was performed for tumors extending proximally to the tracheal bifurcation. For tumors involving the esophagogastric junction, a transhiatal resection was preferred. Peritruncal dissection was carried out with both approaches. For all other tumors, the approach depended on the characteristics of the patient and on local preferences. Gastric-tube reconstruction with a cervical anastomosis was the preferred technique for restoring the continuity of the digestive tract.

\section{PATHOLOGICAL ANALYSIS}

Reports on pathological examination had to describe the tumor type and extension, lymph nodes, and resection margins. In the absence of macroscopic tumor, any abnormal-appearing tissue was paraffin-embedded in total in order to make an adequate assessment for the presence of residual tumor and the effects of therapy.

To grade the response to therapy, we classified the degree of histomorphologic regression into four categories as follows: grade 1 , no evidence of vital residual tumor cells (pathological complete response); grade 2, less than $10 \%$ vital residual tumor cells; grade 3, 10 to $50 \%$; and grade 4 , more than $50 \% .{ }^{11,12}$ If a vital tumor was present at $1 \mathrm{~mm}$ or less from the proximal, distal, or circumferential resection margin, it was considered to be microscopically positive (R1).

\section{FOLLOW-UP}

During the first year after treatment was completed, patients were seen every 3 months. In the second year, follow-up took place every 6 months, and then at the end of each year until 5 years after treatment. Late toxic effects, disease recurrence, and death were documented. Recurrences were scored at the moment of the first recurrence. During follow-up, diagnostic investigations were performed only when recurrence was suspected.

\section{STATISTICAL ANALYSIS}

We calculated that 175 patients were needed in each group in order to detect a difference in median overall survival of 22 months in the chemoradiotherapy-surgery group versus 16 months in the surgery group (two-sided test; alpha level, 0.05 ; beta level, 0.80 ). Stratification factors included histologic tumor type, treatment center, lymph-node $(\mathrm{N})$ stage as determined by endoscopic ultrasonography, and WHO performance score. Block randomization was performed centrally by telephone or at the central trial office, 


\begin{tabular}{|c|c|c|}
\hline Characteristic & $\begin{array}{l}\text { Chemoradiotherapy and Surgery } \\
\qquad(\mathrm{N}=178)\end{array}$ & $\begin{array}{l}\text { Surgery Alone } \\
\qquad(N=188)\end{array}$ \\
\hline \multicolumn{3}{|l|}{ Age $-y r$} \\
\hline Median & 60 & 60 \\
\hline Range & $36-79$ & $36-73$ \\
\hline Male sex - no. (\%) & $134(75)$ & $152(81)$ \\
\hline \multicolumn{3}{|l|}{ Tumor type - no. (\%) } \\
\hline Adenocarcinoma & $134(75)$ & $141(75)$ \\
\hline Squamous-cell carcinoma & $41(23)$ & $43(23)$ \\
\hline Other & $3(2)$ & $4(2)$ \\
\hline \multicolumn{3}{|l|}{ Tumor length $-\mathrm{cm}^{\dagger}$} \\
\hline Median & 4 & 4 \\
\hline Interquartile range & $3-6$ & $3-6$ \\
\hline \multicolumn{3}{|l|}{ Tumor location — no. (\%) † } \\
\hline \multicolumn{3}{|l|}{ Esophagus } \\
\hline Proximal third & $4(2)$ & $4(2)$ \\
\hline Middle third & $25(14)$ & $24(13)$ \\
\hline Distal third & $104(58)$ & $107(57)$ \\
\hline Esophagogastric junction & $39(22)$ & $49(26)$ \\
\hline Missing data & $6(3)$ & $4(2)$ \\
\hline \multicolumn{3}{|l|}{ Clinical T stage - no. $(\%) \ddagger$} \\
\hline cTl & $1(1)$ & $1(1)$ \\
\hline cT2 & $26(15)$ & $35(19)$ \\
\hline cT3 & $150(84)$ & $147(78)$ \\
\hline cT4 & 0 & $1(1)$ \\
\hline Could not be determined $\mathbb{\Omega}$ & $1(1)$ & $4(2)$ \\
\hline \multicolumn{3}{|l|}{ Clinical N stage - no. (\%) } \\
\hline No & $59(33)$ & $58(31)$ \\
\hline $\mathrm{Nl}$ & $116(65)$ & $120(64)$ \\
\hline Could not be determined $\mathbb{\Omega}$ & $3(2)$ & $10(5)$ \\
\hline \multicolumn{3}{|c|}{ WHO performance status score - no. (\%)\| } \\
\hline 0 & $144(81)$ & $163(87)$ \\
\hline 1 & $34(19)$ & $25(13)$ \\
\hline
\end{tabular}

* Percentages may not add up to 100 because of rounding. WHO denotes World Health Organization.

$\uparrow$ Tumor length and location were determined by means of endoscopy.

$\mp$ Clinical tumor (CT) stage was assessed by means of endoscopic ultrasonography or computed tomography (CT) and was classified according to the International Union against Cancer (UICC) tumor-node-metastasis (TNM) classification. ${ }^{9}$

$\int$ This category included patients in whom the tumor could not be fully investigated by means of a transducer for endoscopic ultrasonography owing to a stenosis caused by the tumor.

I Clinical lymph-node (N) stage was assessed by means of endoscopic ultrasonography, $\mathrm{CT}$, or ${ }^{18} \mathrm{~F}$-fluorodeoxyglucose positron-emission tomography and was classified according to UICC TNM classification. ${ }^{9}$

$\|$ WHO performance status scores are on a scale of 0 to 5 , with lower numbers indicating better performance status; 0 indicates fully active, and 1 unable to carry out heavy physical work.

according to computer-generated randomization lists for each stratum, with random block sizes of 4 or 6 .

Data were analyzed according to the intention- to-treat principle. The primary end point was overall survival. All other described outcomes were secondary end points. No post hoc analyses were performed. Survival was calculated from 
the date of randomization until death. All data collected through December 2010 were included in the analysis, which guaranteed a potential minimal follow-up of 2 years.

The Kaplan-Meier method was used to estimate survival, with the log-rank test to determine significance. A Cox proportional-hazards model was used to estimate the treatment effect with adjustment for prognostic factors for survival. Moreover, Cox models were used to identify possible interactions in treatment effect between subgroups, both with and without adjustment for prognostic factors. Subgroups were predefined according to sex, histologic subtype of tumor, clinical N stage, and WHO performance score. Statistical analysis was performed with the use of SPSS software, version 17.0 (SPSS).

\section{RESULTS}

CHARACTERISTICS OF THE PATIENTS

From March 2004 through December 2008, we enrolled 368 patients in the study, of whom 180 were randomly assigned to the chemoradiotherapy-surgery group, and 188 to the surgery group. Two patients who were randomly assigned to the chemoradiotherapy-surgery group withdrew consent and were not included in the analysis (Fig. 1).

Prognostic factors were well balanced between the two treatment groups (Table 1). In both groups, the median age was 60 years; 134 of 178 patients (75\%) in the chemoradiotherapysurgery group were men, as compared with 152 of 188 patients $(81 \%)$ in the surgery group. Most patients (275 of 366 [75\%]) had an adenocarci-

\begin{tabular}{|c|c|c|}
\hline Event & $\begin{array}{l}\text { Chemoradiotherapy } \\
\text { and Surgery } \\
(\mathrm{N}=171)\end{array}$ & $\begin{array}{l}\text { Surgery Alone } \\
(N=186)\end{array}$ \\
\hline \multicolumn{3}{|c|}{ Postoperative events — no. of patients/total no. $(\%) \dagger$} \\
\hline Pulmonary complications & $78 / 168(46)$ & $82 / 186(44)$ \\
\hline Cardiac complications $\int$ & $36 / 168(21)$ & $31 / 186(17)$ \\
\hline Chylothorax 9 & $17 / 168(10)$ & $11 / 186(6)$ \\
\hline Mediastinitis $\|$ & $5 / 168(3)$ & $12 / 186(6)$ \\
\hline Anastomotic leakage*** & $36 / 161(22)$ & $48 / 161(30)$ \\
\hline \multicolumn{3}{|l|}{ Death } \\
\hline In hospital & $6 / 168(4)$ & $8 / 186(4)$ \\
\hline After 30 days & $4 / 168(2)$ & $5 / 186(3)$ \\
\hline \multicolumn{3}{|c|}{ Events of any grade during chemoradiotherapy — no. of patients (\%) } \\
\hline Anorexia & $51(30)$ & \\
\hline Alopecia & $25(15)$ & \\
\hline Constipation & $47(27)$ & \\
\hline Diarrhea & $30(18)$ & \\
\hline Esophageal perforation & $1(1)$ & \\
\hline Esophagitis & $32(19)$ & \\
\hline Fatigue & $115(67)$ & \\
\hline Nausea & $91(53)$ & \\
\hline Neurotoxic effects & $25(15)$ & \\
\hline Vomiting & $43(25)$ & \\
\hline Leukopenia & $103(60)$ & \\
\hline Neutropenia & $16(9)$ & \\
\hline Thrombocytopenia & $92(54)$ & \\
\hline
\end{tabular}




\begin{tabular}{|c|c|}
\hline Event & $\begin{array}{r}\text { Chemoradioth } \\
\text { and Surge } \\
(\mathrm{N}=171)\end{array}$ \\
\hline \multicolumn{2}{|c|}{ Events of grade $\geq 3$ during chemoradiotherapy — no. of patients (\%) } \\
\hline Anorexia & $9(5)$ \\
\hline Constipation & $1(1)$ \\
\hline Diarrhea & $2(1)$ \\
\hline Esophageal perforation & $1(1)$ \\
\hline Esophagitis & $2(1)$ \\
\hline Fatigue & $5(3)$ \\
\hline Nausea & $2(1)$ \\
\hline Vomiting & $1(1)$ \\
\hline Leukopenia & $11(6)$ \\
\hline Neutropenia & $4(2)$ \\
\hline Thrombocytopenia & $1(1)$ \\
\hline
\end{tabular}

* Adverse events were graded according to the National Cancer Institute's Common Terminology Criteria for Adverse Events, version 3.0.10

$\dagger$ Of the 171 patients who received treatment with chemoradiotherapy, 168 underwent surgery.

+ Pulmonary complications were pneumonia (isolation of pathogen from sputum culture and a new or progressive infiltrate on chest radiograph), serious atelectasis (lobar collapse on chest radiograph), pneumothorax (collection of air between the visceral and parietal pleural surfaces, requiring drainage), pleural effusion (collection of fluid between the visceral and parietal pleural surfaces, requiring drainage), pulmonary embolus (embolus detected on spiral CT or a ventilation-perfusion mismatch on a lung scintigram), and acute respiratory failure (partial pressure of arterial oxygen $<60 \mathrm{~mm} \mathrm{Hg}$ while breathing ambient air).

$\int$ Cardiac complications were arrhythmia (any change in rhythm on the electrocardiogram, requiring treatment), myocardial infarction (two or three of the following: previous myocardial infarction, electrocardiographic changes suggesting myocardial infarction, or enzyme changes suggesting myocardial infarction), and left ventricular failure (marked pulmonary edema on a chest radiograph).

I Chylothorax was recorded when elevated levels of triglycerides in intrathoracic fluid ( $>1 \mathrm{mmol}$ per liter [ $89 \mathrm{mg}$ per deciliter]) were found.

|| Mediastinitis was scored when reported by the local investigator.

*:* Anastomotic leakages were recorded when they were diagnosed on physical or radiologic examination in the patients who underwent resection. Leakage was classified as subclinical if it was diagnosed on radiologic examination or endoscopy and as clinical if a salivary fistula was present.

noma. In both groups, the median tumor length was $4 \mathrm{~cm}$. Most tumors were located in the distal esophagus (in 211 of 366 patients [58\%]) or at the esophagogastric junction (in 88 [24\%]). In the chemoradiotherapy-surgery group, 116 of 178 patients $(65 \%)$ had positive lymph nodes as determined by endoscopic ultrasonography, as compared with 120 of 188 (64\%) in the surgery group.

\section{DELIVERY AND TOXIC EFFECTS OF CHEMORADIOTHERAPY}

Seven patients (4\%) in the chemoradiotherapysurgery group did not receive any chemoradiotherapy: 5 because of disease progression before commencing therapy and 2 because they de- clined the therapy. A total of 162 patients (91\%) received the full treatment regimen of five cycles of chemoradiotherapy, and 164 (92\%) received the full dose of radiotherapy. Two patients (1\%) received a higher dose of radiotherapy (45.0 and 54.0 Gy, respectively). The most common reason for not completing all chemotherapy cycles was a low platelet count.

In 12 of 171 patients $(7 \%)$ who received treatment in the chemoradiotherapy-surgery group, grade 3 hematologic toxic effects were observed; a grade 4 hematologic toxic effect and neutropenic fever developed in 1 patient. One patient died while awaiting surgery after chemoradiotherapy, probably owing to a perforation of the esophagus, accompanied by major hemorrhage in the 
absence of thrombocytopenia. All other major nonhematologic toxic effects of grade 3 or higher occurred in less than $13 \%$ of patients in this group. All serious adverse events that occurred during treatment are summarized in Table 2.

\section{SURGERY}

In the chemoradiotherapy-surgery group, 168 patients $(94 \%)$ underwent surgery, as compared with $186(99 \%)$ in the surgery group $(\mathrm{P}=0.01)$. Reasons for not undergoing surgery were the patient's decision ( 2 patients in the chemoradiotherapy-surgery group), disease progression during treatment ( 7 in the chemoradiotherapy-surgery group and 1 in the surgery group), diagnosis of a second cancer before surgery ( 1 in the surgery group), and death before surgery due to toxic effects of chemoradiotherapy (1). No patients were considered medically unfit for surgery.

The median time between randomization and surgery was 97 days in the chemoradiotherapysurgery group and 24 days in the surgery group. The median time between the end of chemoradiotherapy and surgery was 6.6 weeks (interquartile range, 5.7 to 7.9 ). In 7 of 168 patients (4\%) in the chemoradiotherapy-surgery group, a resection was not possible because the primary tumor or lymph nodes were identified during surgery as unresectable, as compared with 25 of 186 patients $(13 \%)$ in the surgery group $(\mathrm{P}=0.002)$.

Postoperative complications are summarized in Table 2. No significant differences in the occurrence of complications were found between the two treatment groups. Six of 168 patients (4\%) in the chemoradiotherapy-surgery group died in the hospital, as did 8 of $186(4 \%)$ in the surgery group $(\mathrm{P}=0.70)$. Four patients $(2 \%)$ in the chemoradiotherapy-surgery group died within 30 days after surgery, as compared with $5(3 \%)$ in the surgery group $(\mathrm{P}=0.85)$.

\section{PATHOLOGICAL ASSESSMENT}

An R0 resection was achieved in 148 of 161 patients (92\%) in the chemoradiotherapy-surgery group, as compared with 111 of $161(69 \%)$ in the surgery group $(\mathrm{P}<0.001)$. A pathological complete response (ypTON0; y denotes underwent neoadjuvant chemoradiotherapy, and $\mathrm{p}$ denotes by pathological assessment) was seen in the resection specimens from 47 patients $(29 \%)$ in the chemoradiotherapy-surgery group. A pathological complete response was observed in 28 of 121 patients with adenocarcino- ma (23\%) versus 18 of 37 with squamous-cell carcinoma (49\%) $(\mathrm{P}=0.008)$. A median of $15 \mathrm{lymph}$ nodes were resected in patients in the chemoradiotherapy-surgery group, as compared with 18 in patients in the surgery group $(\mathrm{P}=0.77)$. One or more positive lymph nodes in the resection specimen were found in 50 patients $(31 \%)$ in the chemoradiotherapy-surgery group, as compared with 120 patients (75\%) in the surgery group $(\mathrm{P}<0.001)$. The pathological findings in all resection specimens are summarized in Appendix 2 in the Supplementary Appendix.

\section{SURVIVAL}

For surviving patients, the median follow-up was 45.4 months (range, 25.5 to 80.9). Of the $61 \mathrm{pa}-$ tients in the chemoradiotherapy-surgery group who underwent resection and died after having been discharged, 52 (85\%) died from recurrent cancer and 9 (15\%) from other causes (2 from sepsis, 2 from cardiac failure, 2 from respiratory insufficiency, 1 from kidney failure, 1 from a second primary tumor, and 1 after reconstructive surgery for a persistent postoperative neo-esophagotracheal fistula). Of the 83 patients in the surgery group who underwent resection and died after having been discharged, 78 (94\%) died from recurrent cancer, 4 (5\%) from other causes (2 from cardiac failure, 1 from respiratory failure, and 1 from a thromboembolic event), and 1 from an unknown cause $(\mathrm{P}=0.14)$. The median disease-free survival for patients who underwent resection was not reached in the chemoradiotherapy-surgery group and was 24.2 months in the surgery group (hazard ratio, 0.498 ; $95 \%$ confidence interval $[\mathrm{CI}], 0.357$ to $0.693 ; \mathrm{P}<0.001$ ).

An intention-to-treat analysis that included all patients showed a median overall survival of 49.4 months in the chemoradiotherapy-surgery group versus 24.0 months in the surgery group $(\mathrm{P}=0.003$ by the log-rank test; hazard ratio, 0.657 ; $95 \% \mathrm{CI}, 0.495$ to 0.871 ) (Fig. 2A). The respective overall survival rates at $1,2,3$, and 5 years were $82 \%, 67 \%, 58 \%$, and $47 \%$ in the chemoradiotherapy-surgery group, as compared with $70 \%, 50 \%, 44 \%$, and $34 \%$ in the surgery group. Adjustment for baseline prognostic factors led to a similar effect estimate (hazard ratio, 0.665 ; $95 \%$ CI, 0.500 to 0.884 ).

Separate curves for overall survival according to histologic subtype (i.e., adenocarcinoma or squamous-cell carcinoma) are shown in Figure 
Figure 2. Kaplan-Meier Plots of Estimated Overall 5-Year Survival.

Panel A shows a Kaplan-Meier plot of the estimated overall 5 -year survival among patients with esophageal or esophagogastric-junction cancer who underwent neoadjuvant chemoradiotherapy (CRT) followed by surgery (178 patients) or surgery alone (188), according to an intention-to-treat analysis. Panel B shows a KaplanMeier plot of the estimated overall 5-year survival among the 134 patients with adenocarcinoma (AC) treated with neoadjuvant chemoradiotherapy followed by surgery and the 141 treated with surgery alone, and the 41 patients with squamous-cell carcinoma (SCC) treated with chemoradiotherapy followed by surgery and the 43 treated with surgery alone, according to an intention-to-treat analysis. Other tumor types were excluded from this analysis.

$2 \mathrm{~B}$. The benefit of neoadjuvant chemoradiotherapy on survival was consistent across subgroups, without any significant interaction identified. Hazard ratios for the subgroup effects, with and without adjustment for baseline covariates, are shown in Figure 3.

\section{DISCUSSION}

This large, randomized trial of neoadjuvant chemoradiotherapy in patients with esophageal or esophagogastric-junction cancer showed significantly better overall and disease-free survival among patients who received a chemoradiotherapy regimen based on carboplatin and paclitaxel, followed by surgery, as compared with those treated with surgery alone. The chemoradiotherapy was associated with a low frequency of high-grade toxic effects and could be given as an outpatient treatment. The preoperative treatment did not result in higher postoperative morbidity or early mortality in this group, as compared with the surgery group. Patients treated with neoadjuvant chemoradiotherapy followed by surgery had a 34\% lower risk of death during follow-up (hazard ratio, 0.657).

The chemoradiotherapy regimen was designed on the basis of our experience in a previous phase 2 study, ${ }^{7}$ which used the same dosages of radiotherapy and chemotherapy. In that study, it was possible to administer this regimen on an outpatient basis, and all the patients had resection margins that were microscopically negative. On the basis of these results, an alteration of the chemoradiotherapy regimen was not thought to be necessary.

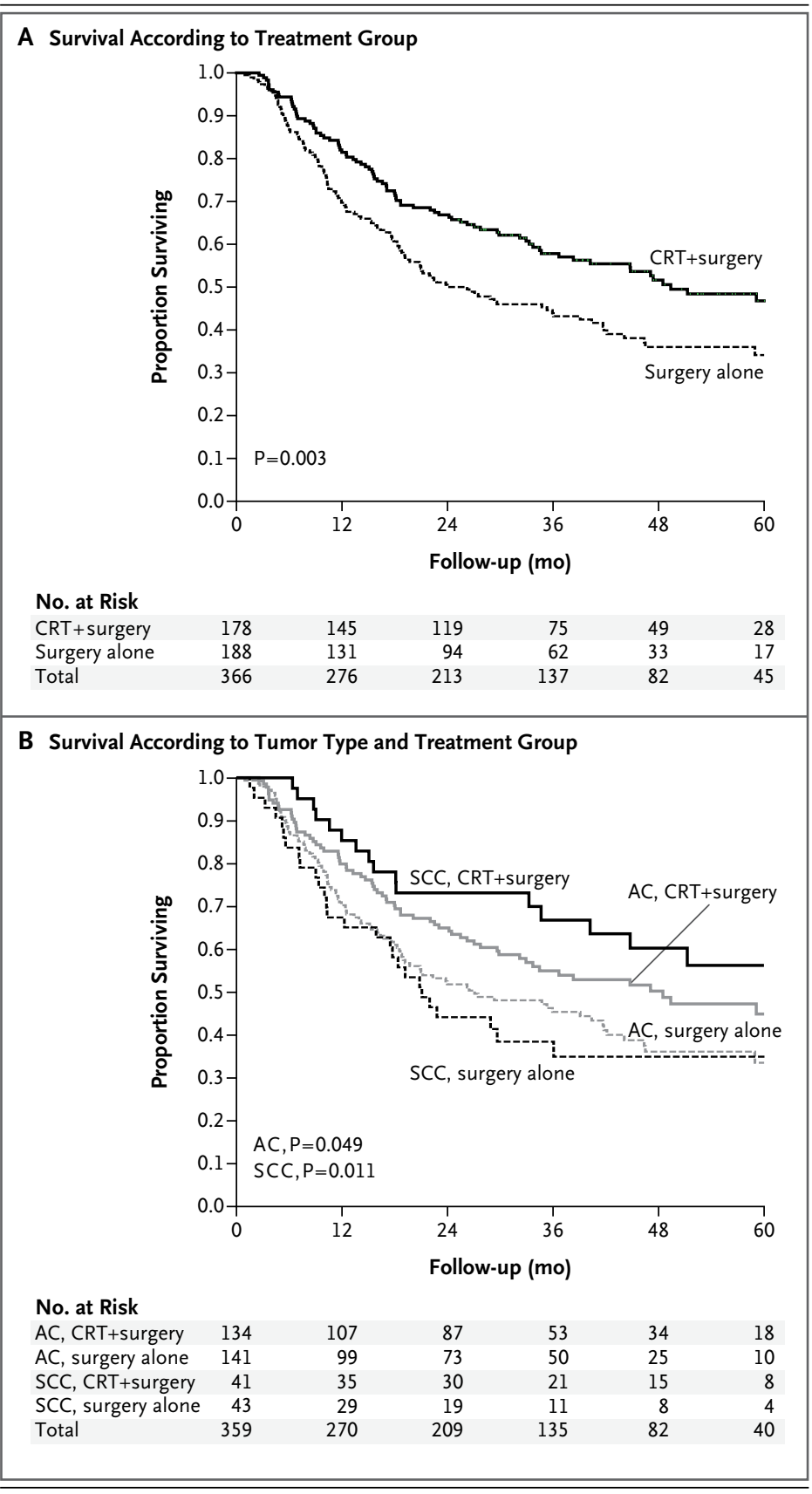

The present study was designed to detect a difference in median survival of 6 months in favor of the combined regimen of chemoradiotherapy and surgery, as compared with surgery alone (22 months vs. 16 months). The observed survival in both groups was superior to the anticipated survival and to that reported in earlier randomized trials. ${ }^{6,13-17}$ In line with the results of other studies, the survival of patients treated with surgery alone has improved, ${ }^{18,19}$ probably 


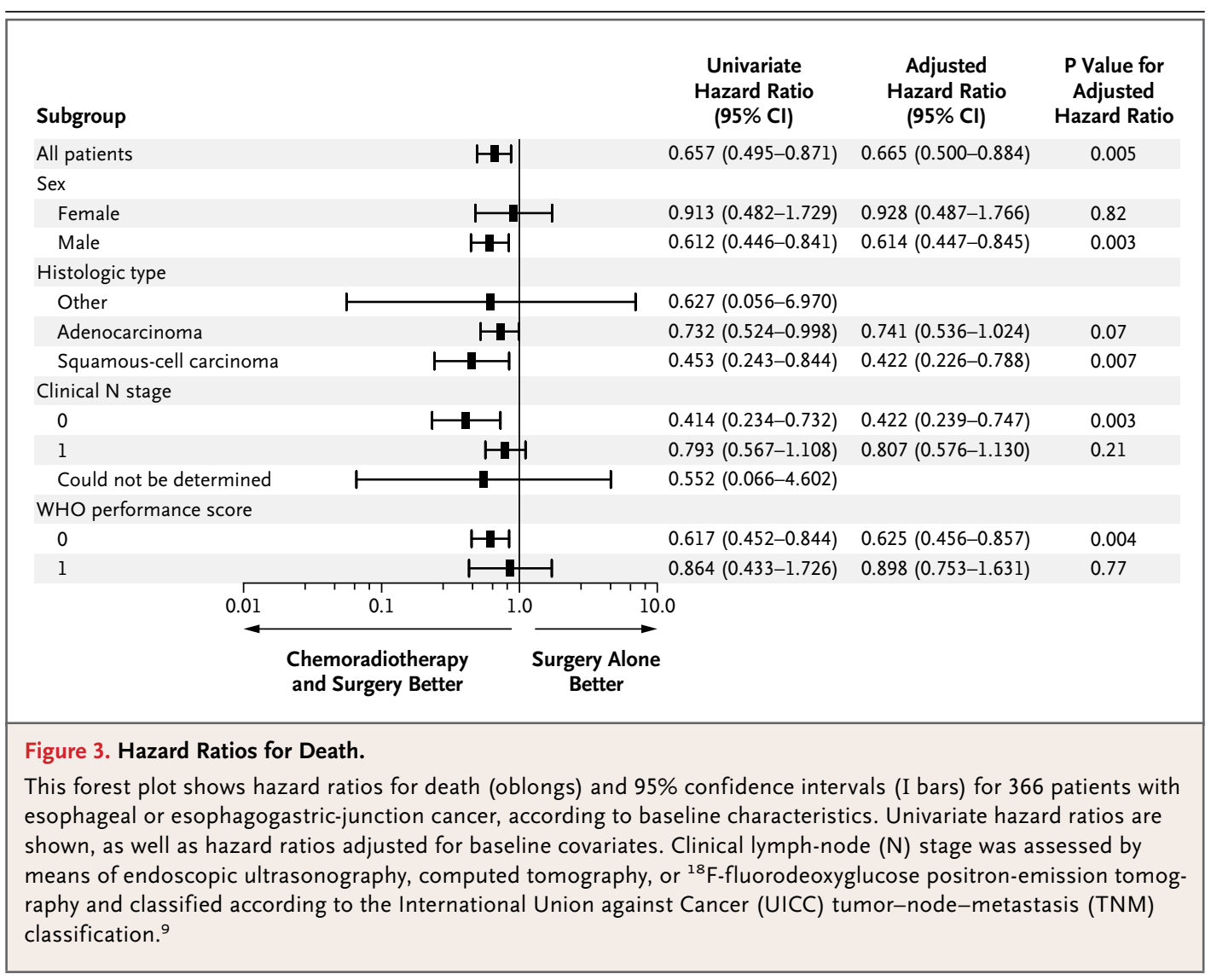

owing to ongoing improvements in surgical techniques, patient selection, and staging methods over the years. The difference in overall survival in the present study is not due to poor survival in the surgery group but can clearly be attributed to improved survival in the chemoradiotherapysurgery group.

In the chemoradiotherapy-surgery group, 94\% of patients underwent surgery, and $90 \%$ of tumors could be resected. In the surgery group, $99 \%$ of patients underwent surgery, and $86 \%$ underwent resection. These percentages indicate that the preoperative chemoradiotherapy did not significantly change the individual chance of undergoing a resection. ${ }^{14,15,17}$ Postoperative complication rates, although similar between groups, were higher than expected and higher than reported in other studies. ${ }^{20}$ We could not find a plausible explanation for this finding, other than the fact that all postoperative events were meticulously recorded. This relatively high incidence of postoperative events in both treatment groups did not result in an increased postoperative mor- tality, which was low and similar in the two groups.

Complete remission in both the primary tumor and the lymph nodes (ypT0N0) was the best possible pathological outcome of chemoradiotherapy. The observed percentage of patients with a pathological complete response $(29 \%)$ is in line with the reported percentages in other phase 2 and phase 3 studies. ${ }^{7,13,14,18,21}$ The substantial downstaging as a result of chemoradiotherapy is also reflected in the significantly higher percentage of $\mathrm{R} 0$ resections in the chemoradiotherapy-surgery group.

Despite the higher rate of pathological complete response among patients with squamouscell carcinoma, as compared with those with adenocarcinoma, histologic tumor type was not a prognostic factor for survival. That is, patients with adenocarcinoma and patients with squamous-cell carcinoma both benefited from neoadjuvant chemoradiotherapy.

Whether esophageal and esophagogastricjunction tumors should be treated with preop- 
erative chemoradiotherapy or with perioperative chemotherapy, as suggested by the Medical Research Council Adjuvant Gastric Infusional Chemotherapy (MAGIC) trial ${ }^{22}$ and the Actions Concertées dans les Cancer Colorectaux et Digestifs (ACCORD) 07 trial, ${ }^{23}$ is unclear. Both trials included gastric tumors as well as esophagogastric-junction tumors, whereas in the current trial only patients with esophageal or esophagogastric-junction tumors were treated. In the POET trial, only patients with esophagogastric-junction tumors were included and randomly assigned to preoperative chemotherapy or chemoradiotherapy. ${ }^{24}$ In that study, there was a nonsignificant trend in favor of preoperative chemoradiotherapy. Because a substantial percentage of patients in the chemoradiotherapysurgery group in the present study $(22 \%)$ had an esophagogastric-junction tumor, we favor preop- erative chemoradiotherapy for such patients, as was also suggested by the POET study, especially because of the limited toxic effects that were observed with this treatment regimen. In conclusion, preoperative chemoradiotherapy (five courses of carboplatin and paclitaxel, with $41.4 \mathrm{~Gy}$ of concurrent radiotherapy) is safe and leads to a significant increase in overall survival among patients with adenocarcinoma or squamous-cell carcinoma of the esophagus or esophagogastric junction.

Supported by the Dutch Cancer Foundation (KWF Kankerbestrijding).

Disclosure forms provided by the authors are available with the full text of this article at NEJM.org.

We thank all the participating patients and all the medical oncologists, radiation oncologists, surgeons, gastroenterologists, pathologists, radiologists, and members of the research support staff at the participating centers who are listed in Appendix 3 in the Supplementary Appendix; and especially Linetta Koppert for her efforts in the trial design.

The authors' full names and degrees are as follows: Pieter van Hagen, M.D., Maarten C.C.M. Hulshof, M.D., Ph.D., Joseph J.B. van Lanschot, M.D., Ph.D., Ewout W. Steyerberg, Ph.D., Mark I. van Berge Henegouwen, M.D., Ph.D., Bas P.L. Wijnhoven, M.D., Ph.D., Dirk J. Richel, M.D., Ph.D., Grard A.P. Nieuwenhuijzen, M.D., Ph.D., Geke A.P. Hospers, M.D., Ph.D., Johannes J. Bonenkamp, M.D., Ph.D., Miguel A. Cuesta, M.D., Ph.D., Reinoud J.B. Blaisse, M.D., Olivier R.C. Busch, M.D., Ph.D., Fiebo J.W. ten Kate, M.D., Ph.D., Geert-Jan Creemers, M.D., Ph.D., Cornelis J.A. Punt, M.D., Ph.D., John T.M. Plukker, M.D., Ph.D., Henk M.W. Verheul, M.D., Ph.D., Ernst J. Spillenaar Bilgen, M.D., Ph.D., Herman van Dekken, M.D., Ph.D., Maurice J.C. van der Sangen, M.D., Tom Rozema, M.D., Katharina Biermann, M.D., Ph.D., Jannet C. Beukema, M.D., Anna H.M. Piet, M.D., Caroline M. van Rij, M.D., Janny G. Reinders, M.D., Hugo W. Tilanus, M.D., Ph.D., and Ate van der Gaast, M.D., Ph.D.

The authors' affiliations are as follows: the Departments of Surgery (P.H., J.J.B.L., B.P.L.W., H.W.T.), Public Health (E.W.S.), Pathology (F.J.W.K., H.D., K.B.), and Radiation Oncology (C.M.R.), Erasmus University Medical Center, and the Department of Medical Oncology, Erasmus University Medical Center/Daniel den Hoed Cancer Center (A.G.), Rotterdam; the Departments of Radiation Oncology (M.C.C.M.H.), Surgery (J.J.B.L., M.I.B.H., O.R.C.B.), Medical Oncology (D.J.R.), and Pathology (F.J.W.K.), Academic Medical Center Amsterdam, the Departments of Surgery (M.A.C.), Medical Oncology (H.M.W.V.), and Radiation Oncology (A.H.M.P.), VU Medical Center Amsterdam, and the Department of Pathology, St. Lucas Andreas Hospital Amsterdam (H.D.), Amsterdam; the Departments of Surgery (G.A.P.N.), Medical Oncology (G.-J.C.), and Radiation Oncology (M.J.C.S.), Catharina Hospital Eindhoven, Eindhoven; the Departments of Medical Oncology (G.A.P.H.), Surgery (J.T.M.P.), and Radiation Oncology (J.C.B.), University Medical Center Groningen, Groningen; the Departments of Surgery (J.J.B.), Medical Oncology (C.J.A.P.), and Radiation Oncology (T.R.), Radboud University Nijmegen Medical Center, Nijmegen; the Departments of Medical Oncology (R.J.B.B.) and Surgery (E.J.S.B.), Rijnstate Hospital Arnhem, and Arnhem Radiotherapeutic Institute (J.G.R.), Arnhem; and Verbeeten Institute Tilburg, Tilburg (T.R.) — all in the Netherlands.

REFERENCES

1. Ferlay J, Shin HR, Bray F, Forman D, Mathers C, Parkin DM. Estimates of worldwide burden of cancer in 2008: GLOBOCAN 2008. Int J Cancer 2010;127:2893-917.

2. Parkin DM, Bray FI, Devesa SS. Cancer burden in the year 2000: the global picture. Eur J Cancer 2001;37:Suppl 8:S4-S66. 3. Devesa SS, Blot WJ, Fraumeni JF Jr. Changing patterns in the incidence of esophageal and gastric carcinoma in the United States. Cancer 1998;83:2049-53.

4. Kelsen DP, Ginsberg R, Pajak TF, et al. Chemotherapy followed by surgery compared with surgery alone for localized esophageal cancer. N Engl J Med 1998; 339:1979-84.

5. Malthaner R, Fenlon D. Preoperative chemotherapy for resectable thoracic esophageal cancer. Cochrane Database Syst Rev 2001;1:CD001556.

6. Urba SG, Orringer MB, Turrisi A, Iannettoni $M$, Forastiere A, Strawderman $M$. Randomized trial of preoperative chemoradiation versus surgery alone in patients with locoregional esophageal carcinoma. J Clin Oncol 2001;19:305-13.

7. van Meerten E, Muller K, Tilanus HW, et al. Neoadjuvant concurrent chemoradiation with weekly paclitaxel and carboplatin for patients with oesophageal cancer: a phase II study. Br J Cancer 2006; 94:1389-94.

8. van Heijl M, van Lanschot JJ, Koppert LB, et al. Neoadjuvant chemoradiation followed by surgery versus surgery alone for patients with adenocarcinoma or squamous cell carcinoma of the esophagus (CROSS). BMC Surg 2008;8:21.

9. International Union against Cancer. TNM classification of malignant tumours. 6th ed. New York: Wiley-Liss, 2002.

10. Trotti A, Colevas AD, Setser A, et al. CTCAE v3.0: development of a comprehensive grading system for the adverse effects of cancer treatment. Semin Radiat Oncol 2003;13:176-81.

11. Mandard AM, Dalibard F, Mandard JC, et al. Pathologic assessment of tumor regression after preoperative chemoradiotherapy of esophageal carcinoma: clinicopathologic correlations. Cancer 1994;73: 2680-6.

12. Chirieac LR, Swisher SG, Ajani JA, et al. Posttherapy pathologic stage predicts sur- 
vival in patients with esophageal carcinoma receiving preoperative chemoradiation. Cancer 2005;103:1347-55.

13. Walsh TN, Noonan N, Hollywood D, Kelly A, Keeling N, Hennessy TP. A comparison of multimodal therapy and surgery for esophageal adenocarcinoma. N Engl J Med 1996;335:462-7. [Erratum, N Engl J Med 1999;341:384.]

14. Bosset JF, Gignoux M, Triboulet JP, et al. Chemoradiotherapy followed by surgery compared with surgery alone in squamous-cell cancer of the esophagus. N Engl J Med 1997;337:161-7.

15. Burmeister BH, Smithers BM, Gebski V, et al. Surgery alone versus chemoradiotherapy followed by surgery for resectable cancer of the oesophagus: a randomised controlled phase III trial. Lancet Oncol 2005;6:659-68.

16. Lin $\mathrm{CC}$, Hsu CH, Cheng JC, et al. Concurrent chemoradiotherapy with twice weekly paclitaxel and cisplatin followed by esophagectomy for locally advanced esophageal cancer. Ann Oncol 2007;18: 93-8.

17. Tepper J, Krasna MJ, Niedzwiecki D et al. Phase III trial of trimodality therapy with cisplatin, fluorouracil, radiotherapy, and surgery compared with surgery alone for esophageal cancer: CALGB 9781. J Clin Oncol 2008;26:1086-92.

18. Lee JL, Park SI, Kim SB, et al. A single institutional phase III trial of preoperative chemotherapy with hyperfractionation radiotherapy plus surgery versus surgery alone for resectable esophageal squamous cell carcinoma. Ann Oncol 2004;15:94754.

19. Portale G, Hagen JA, Peters JH, et al Modern 5-year survival of resectable esophageal adenocarcinoma: single institution experience with 263 patients. J Am Coll Surg 2006;202:588-96.

20. Fiorica F, Di Bona D, Schepis F, et al Preoperative chemoradiotherapy for oesophageal cancer: a systematic review and meta-analysis. Gut 2004;53:925-30.
21. Gannett DE, Wolf RF, Takahashi GW, et al. Neoadjuvant chemoradiotherapy for esophageal cancer using weekly paclitaxel and carboplatin plus infusional 5-fluorouracil. Gastrointest Cancer Res 2007;1: 132-8.

22. Cunningham D, Allum WH, Stenning SP, et al. Perioperative chemotherapy versus surgery alone for resectable gastroesophageal cancer. N Engl J Med 2006; 355:11-20.

23. Ychou M, Boige V, Pignon JP, et al. Perioperative chemotherapy compared with surgery alone for resectable gastroesophageal adenocarcinoma: an FNCLCC and FFCD multicenter phase III trial. J Clin Oncol 2011;29:1715-21.

24. Stahl M, Walz MK, Stuschke M, et al. Phase III comparison of preoperative chemotherapy compared with chemoradiotherapy in patients with locally advanced adenocarcinoma of the esophagogastric junction. J Clin Oncol 2009;27:851-6.

Copyright () 2012 Massachusetts Medical Society. 